\title{
Urothelial bladder carcinoma with major clinical presentation as overactive bladder, without hematuria: case report and literature review
}

\author{
Alexander de J. Rafaelano M. ${ }^{1}$, Junior J. Araiza Navarro ${ }^{1 *}$, María Isabel Tolentino Sosa ${ }^{2}$, \\ Fernando López Reyes ${ }^{3}$, Marlene de la Peña Gutiérrez ${ }^{4}$
}

\begin{abstract}
${ }^{1}$ Gynecology and Obstetrics Resident at the Postgraduate School of Naval Sanity, Universidad Naval and the Hospital General Naval de Alta Especialidad, Secretaría de Marina Armada de México (SEMAR)

${ }^{2}$ Gynecologist-Obstetrician, Gynecological Urology, Chief of the Urogynecology Service of the Hospital General Naval de Alta Especialidad, Secretaría de Marina Armada de México (SEMAR)

${ }^{3}$ Urologist, Kidney Transplant Specialist, of the Hospital General Naval de Alta Especialidad, Secretaría de Marina Armada de México (SEMAR)

${ }^{4}$ Gynecologist-Obstetrician, Specialist in Maternal-Fetal Medicine, Hospital General Naval de Alta Especialidad, Secretaría de Marina Armada de México (SEMAR)
\end{abstract}

Received: 19 July 2018

Accepted: 01 September 2018

\section{*Correspondence:}

Dr. Junior J. Araiza Navarro,

E-mail: joelara16@hotmail.com

Copyright: (c) the author(s), publisher and licensee Medip Academy. This is an open-access article distributed under the terms of the Creative Commons Attribution Non-Commercial License, which permits unrestricted non-commercial use, distribution, and reproduction in any medium, provided the original work is properly cited.

\begin{abstract}
The urothelial carcinoma is the most common type of bladder cancer, comprising approximately $90 \%$ of cases in the United States. The most common symptom of bladder cancer is macroscopic hematuria, increased urinary frequency, urgency, or irritative symptoms may occur. Generally, occurs in elderly people, about 9 out of 10 people are over 55 years old, with the average age at diagnosis of 73 years. Males are more likely than women to have this neoplasm with a probability of 1 in 27 (for women the probability is 1 in 89). Most bladder cancers begin in the inner layer, also called the urothelium or transitional epithelium. As it advances, it invades the layers of the bladder and can invade adjacent structures, often metastasizing to distant lymph nodes, bones, lungs or the liver. Among the cancers that originate in the bladder authors have: Urothelial carcinoma (transitional cell carcinoma), squamous cell carcinoma, adenocarcinoma, small cell carcinoma, sarcoma. Hematuria occurs in the majority of patients with urothelial carcinoma. Symptoms such as dysuria, frequency, urgency and pain may also occur, or it may also be asymptomatic. In this case report, an atypical presentation of bladder cancer is shown, simulating the symptomatology of a Hyperactive Bladder Syndrome.
\end{abstract}

Keywords: Hematuria, Overactive bladder, Urinary Bladder Cancer

\section{INTRODUCTION}

Bladder cancer is a malignant neoplasm that originates in the bladder mucosa, the most frequent histopathological types are usually in order of frequency: urothelial carcinoma of the bladder (up to $90 \%$ of bladder cancers), adenocarcinoma of the bladder and Squamous cell carcinoma of the bladder. ${ }^{1}$ Bladder cancer is the sixth most common cancer in the United States of America, accounting for $4.6 \%$ of all new cases of cancer. ${ }^{2}$ Among the risk factors associated with bladder cancer, authors found smoking, perhaps the most important risk factor 
related to lifestyle and modifiable. ${ }^{3}$ It is also known that exposure to aromatic amines, alanine dyes, Acrolein, arsenic, nitrites and nitrates increase the relative risk of bladder cancer. ${ }^{4}$

Several studies have suggested a relationship of the Human Papillomavirus with bladder cancer, a metaanalysis that included 52 studies and 2855 cases of bladder cancer, revealed that the prevalence of Human Papillomavirus was $17 \%$, being the serotype, more associated the HPV $-16 .{ }^{5}$

Another important risk factor is the antecedent of pelvic radiotherapy for the management of rectal and cervical cancers, however, this relationship has not been observed in the different studies, and the magnitude of the risk seems to be small. ${ }^{6.7}$ However, in other studies, patients with a history of pelvic radiation therapy, who develop urothelial bladder cancer, appear to have more advanced tumors with poorer survival than age and stage-matched controls. ${ }^{8-12}$

The incidence of this neoplasm increases with age from 142 to 296 per 100,000 in men 65 to 69 years and 85 and more, respectively, and from 33 to 74 per 100,000 in women of the same age groups. ${ }^{13}$

\section{CASE REPORT}

It is a female patient of 39 years of age. Family history: Grandfather with a history of gastric cancer, father with systemic arterial hypertension. Non-pathological Personal Background: native and resident of Mexico City, smoking, alcoholism denied, complete immunizations. Pathological Personal Background: denied chronic degenerative, denied transfusion, surgical: hemorrhoidectomy on July 29, 2016, 2 cesareans, Bilateral Tubal Obstruction. Gynecological Background: menarche at 11 years, cycles $28 \times 7$, uses 5 towels a day, denies dysmenorrhea. Cervical cytology one previous month without report, colposcopy one month before without alterations, gestations 2, caesarean 2 .

She came to the clinic presenting the following symptoms: urinary frequency onset of 20 times a day with nocturia of 2 times. Urinary incontinence of urgency 2 times a week with loss in small jet of 6 months of evolution. In addition to irritative symptoms and feeling of incomplete emptying. It refers postvoid drip. Therefore, the clinical diagnosis of overactive bladder is integrated. Behavioral therapy is indicated, and the severity begins with anticholinergic management. Bladder, kidney ultrasound and urine culture are requested.

\section{Bladder ultrasound}

Bladder with physiological repletion at the time of the study. Its dimensions of $122 \times 89 \times 120 \mathrm{~mm}$ with an initial volume of $687 \mathrm{cc}$. Postmiction diameters 104 x 64 x $107 \mathrm{~mm}$, inside is observed echogenic image of irregular edges of 86 x $37 \mathrm{~mm}$ does not present vascularity with color Doppler. It is located on the bladder floor and right wall, regular wall and defined in ceiling with a thickness of $3.7 \mathrm{~mm}$.

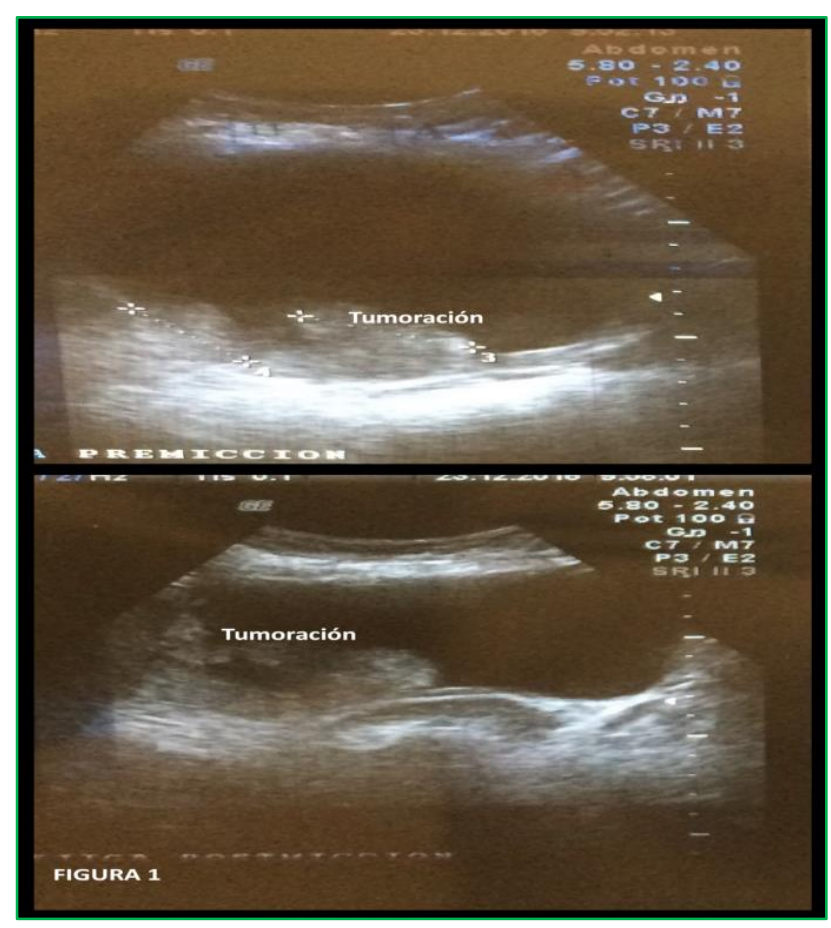

Figure 1: Gynecological ultrasound: an echogenic image of irregular edges corresponding to the bladder tumor is observed.

\section{General urine test}

No evidence of microscopic hematuria.

\section{Uroculture}

Escherichia coli $>100000 \mathrm{CFU}$. It is treated with nitrofurantoin. With uroculture control.

\section{Urotomography with contrast}

The bladder is distended, it is defined solid lesion with irregular edges that extend over the right posterolateral wall with approximate measurements of $61 \times 67 \mathrm{~mm}$ in the axial plane and $57 \mathrm{~mm}$ in the cephalocaudal plane, with $31 \mathrm{UH}$ in the phase simple and $81 \mathrm{UH}$ in the venous phase. In the phase of elimination, it is characterized as a prominent filling defect. In the right iliac chain, ganglionic growth of $11 \mathrm{~mm}$ of short axis is observed, which reinforces significantly after the application of intravenous contrast medium.

\section{Transurethral resection of bladder tumor}

Finding of a multicentric bladder tumor in $70 \%$ of the bladder walls, resecting only $50-60 \%$ of said tumor. 


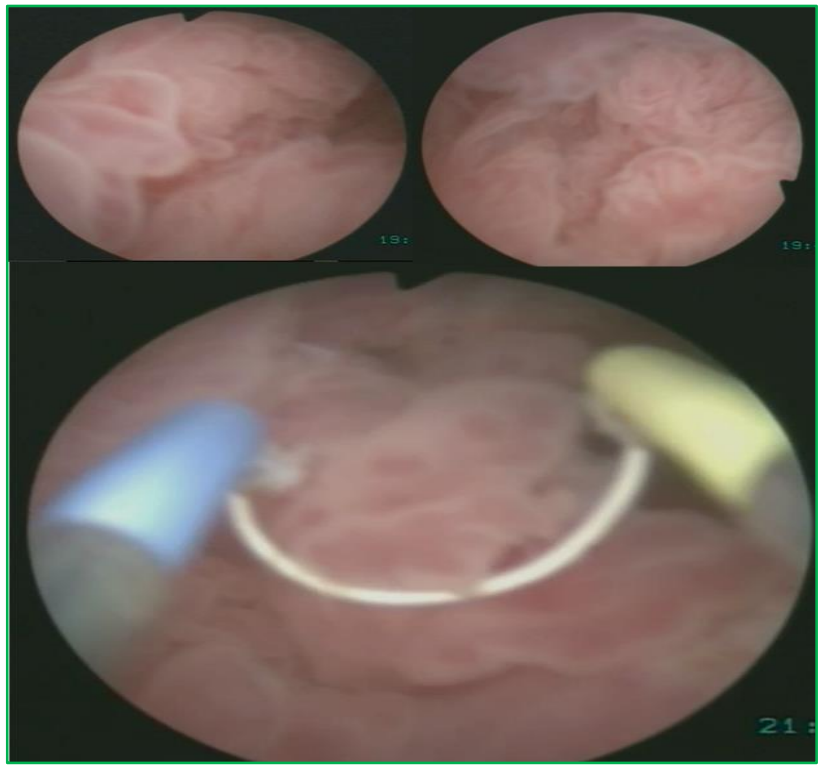

Figure 2: Cystoscopic image of transurethral resection of bladder tumor.

\section{Histopathology}

Malignant neoplastic lesion formed by papillae of variable size, are lined by transitional aspect epithelium with disorganization of architecture, shows loss of polarity with atypical mitosis throughout the thickness of the epithelium, the nucleus is ovoid with atypia of moderate degree. There is no infiltration to the stem, there is no bladder wall tissue so it is not possible to rule out an infiltration zone. Diagnosis: high grade papillary urothelial carcinoma, without infiltration to the muscularis propria in the tissue studied.

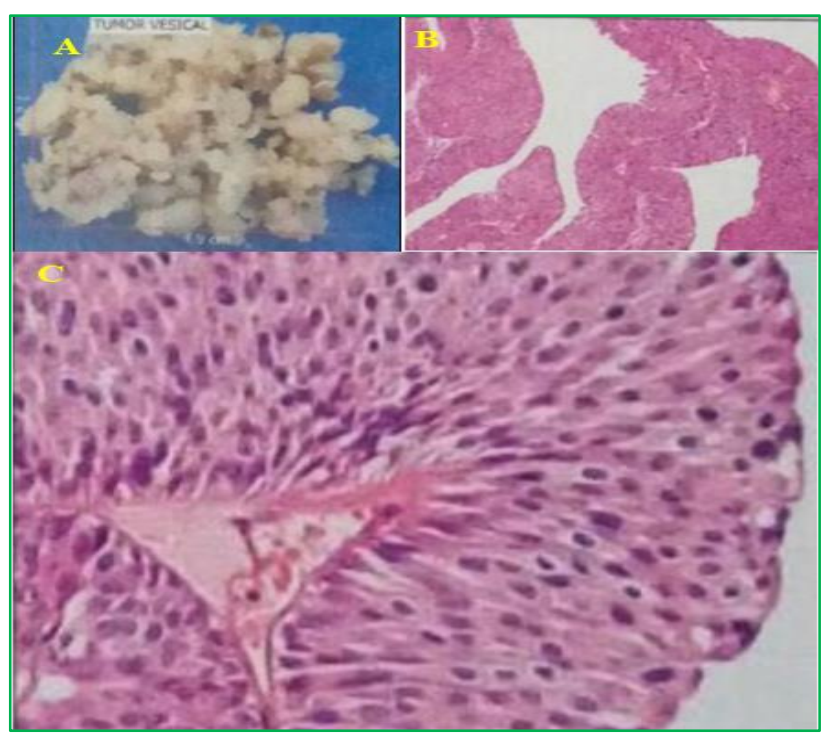

There are papillae of variable size, covered by transitional aspect epithelium with disorganization of the architecture.

Figure 3: A-macroscopic, B-panoramic and Cmicroscopic detail of the malignant neoplastic lesion.

\section{Second time of bladder tumor resection}

Without being able to resect the tumor in its entirety due to its large volume and depth that caused significant trans operative bleeding.

The plan to continue is to perform radical cystectomy, currently the patient carries transurethral catheter until the next surgical time.

\section{DISCUSSION}

Urothelial carcinoma is the most common type of bladder cancer, comprising approximately $90 \%$ of cases in the United States. ${ }^{14}$ Bladder cancer is the most common malignancy of the urinary tract, being the seventh most common cancer. in men and number 17 in women. In Latin America, bladder cancer has an incidence of 5.6 per 100,000 inhabitants, in Mexico it corresponds to $14.4 \%$ of genitourinary cancers, ranking as the fourth most frequent. ${ }^{15}$ The prevalence of bladder cancer ranges from $13 \%$ to $35 \%$ in patients presenting with gross hematuria and between $5 \%$ and $10 \%$ in patients presenting with microscopic hematuria. ${ }^{16}$ Overactive bladder, is a clinical diagnosis defined by the International Continence Society as the presence of "urinary urgency, often accompanied by frequency and nocturia, with or without urge urinary incontinence, in the absence of a urinary tract infection or another pathology. ${ }^{17}$

Patients with urothelial carcinoma commonly present with macroscopic or microscopic hematuria up to $73.2 \% .{ }^{18}$ Lower urinary tract symptoms, such as urinary frequency or dysuria, may also occur. ${ }^{19}$ In present patient's case, the main clinical presentation was symptoms of overactive bladder. Overactive bladder is a common condition that greatly affects the quality of life and, the evaluation of the patient must begin with a determination of the degree to which the symptoms impact on the quality of life of the patient. For this, quality of life questionnaires have been standardized. ${ }^{20} \mathrm{It}$ is also important to evaluate the medical and surgical history thoroughly. The physical examination can elucidate the underlying medical conditions that contribute to the symptoms. The pelvic examination should evaluate signs of atrophy, prolapse of pelvic organs, evaluation of pelvic floor muscle strength, and any anatomical abnormalities, as was done in this patient. $^{21}$

Laboratory tests include urinalysis and possibly urine cytology if bladder irritative symptoms are significant and microhematuria is present in the urinalysis. Urodynamic tests may be indicated to further investigate overactive bladder symptoms as well as electromyography may be useful in assessing muscle activity. ${ }^{18}$ However, in this case the findings of the general urine test negative to hematuria decreased the diagnostic probabilities of malignancy, and treatment with antibiotics was proceeded by the results of the urine 
culture. Subsequently, the images found in ultrasound led us to suspect a diagnosis of a bladder tumor. The evaluation in case of suspicion of bladder cancer includes a clinical and physical history, urinalysis, urine cytology, cystoscopy, and the image of the upper tract with computed tomography. ${ }^{14}$ The general urinalysis in case of suspicion of bladder cancer, is performed in search of hematuria since cancer of the bladder or upper genitourinary tract is perhaps the most worrying cause. ${ }^{22}$

The documented risk factors for the development of bladder cancer include the history of smoking, exposure to diesel fuel and fumes, aromatic amines, dry cleaning fluids, radioactive materials and arsenic, or alkylating agents, such as cyclophosphamide, and the reduction of DNA repair capacity. ${ }^{23}$ With the ultrasonographic findings it was decided to perform urotomography as diagnostic support, however the cornerstone of the diagnosis and subsequent monitoring of bladder cancer is the cystoscopic examination of the lower urinary tract. Specifically, cystoscopy with white light, which remains the gold standard, despite its limitations. Its sensitivity ranges from $62 \%$ to $84 \%$ and the specificity ranges from $43 \%$ to $98 \% .{ }^{16}$ With the findings during the cystoscopy it was decided to start transurethral resection with the premise that transurethral resection of bladder tumors under regional or general anesthesia is the gold standard to excise (and potentially cure) all visible tumors and to provide specimens for the staging and classification of bladder cancer. ${ }^{24}$ With the histopathological examination, the variant of bladder cancer that authors are facing in this case could be identified, being of great help since the pathological identification of the cancer variants Bladder contributes greatly to decision-making with respect to intravesical treatments, chemotherapy, and to decide the time of radical cystectomy and urinary diversion. The early identification of pathological characteristics of aggressive variants is important, such as high-grade recurrent carcinoma in situ, micropapillary disease, or extensive high-grade $\mathrm{T} 1$ disease, since early cystectomy can be justified in these patients. In present case, the difficulties in the transurethral resection of the tumor by cystoscopy led us to decide to perform a radical cystectomy which is still in the programming protocol.

\section{CONCLUSION}

Bladder cancer can give varied clinical symptoms, and expecting to find hematuria in a urine test, can lead to a delay in the diagnosis however imaging tests are of great help to support the suspected diagnosis. As mentioned before, cystoscopy is still very helpful for taking samples and staging by histopathology, since depending on the histological variant, an optimal treatment can be given and a prognosis can be identified. Authors must never forget to follow the study protocols supported in the clinical guidelines and always look for differential diagnoses, since authors can find clinical cases that come out of the ordinary.
Funding: No funding sources

Conflict of interest: None declared

Ethical approval: The study was approved by the Institutional Ethics Committee of HOSGENAES

\section{REFERENCES}

1. Xie D, Zhang H, Shang C. Long non-coding RNA CDKN2B antisense RNA 1 gene inhibits Gemcitabine sensitivity in bladder urothelial carcinoma. J Cancer. 2018;9(12):2160-6.

2. National Cancer Institute Cancer of the urinary bladder. 2016. Available at: http://seer.cancer.gov/statfacts/html/urinb.html.

3. IARC Working Group on the Evaluation of Carcinogenic Risks to Humans, World Health Organization, International Agency for Research on Cancer. Tobacco smoke and involuntary smoking. IARC. 2004.

4. Pashos CL, Botteman MF, Laskin BL, Redaelli A. Bladder cancer: epidemiology, diagnosis, and management. Cancer Pract. 2002;10(6):311-22.

5. Li N, Yang L, Zhang Y, Zhao P, Zheng T, Dai M. Human papillomavirus infection and bladder cancer risk: a meta-analysis. J Infect Dis. 2011;204(2):21723.

6. Kleinerman RA, Boice Jr JD, Storm HH, Sparen P, Andersen A, Pukkala E, et al. Second primary cancer after treatment for cervical cancer. An Int Cancer Registries Study. Cancer. 1995;76(3):442-52.

7. Travis LB, Curtis RE, Fraumeni Jr JF, Boice Jr JD, Storm H, Andersson M, et al. Risk of second malignant neoplasms among long-term survivors of testicular cancer. J Nat Cancer Institute. 1997;89(19):1429-39.

8. Sandhu JS, Vickers AJ, Bochner B, Donat SM, Herr HW, Dalbagni G. Clinical characteristics of bladder cancer in patients previously treated with radiation for prostate cancer. BJU Int. 2006;98(1):59-62.

9. Bostrom PJ, Soloway MS, Manoharan M, Ayyathurai R, Samavedi S. Bladder cancer after radiotherapy for prostate cancer: detailed analysis of pathological features and outcome after radical cystectomy. J Urol. 2008;179(1):91-5.

10. Shah SK, Lui PD, Baldwin DD, Ruckle HC. Urothelial carcinoma after external beam radiation therapy for prostate cancer. J Urol. 2006;175:2063.

11. Yee DS, Shariat SF, Lowrance WT, Sterbis JR, Vora $\mathrm{KC}$, Bochner $\mathrm{BH}$, et al. Impact of previous radiotherapy for prostate cancer on clinical outcomes of patients with bladder cancer. J Urol. 2010;183(5):1751-6.

12. Keehn A, Ludmir E, Taylor J, Rabbani F. Incidence of bladder cancer after radiation for prostate cancer as a function of time and radiation modality. World $\mathbf{J}$ Urol. 2017;35:713.

13. 13.- Hinotsu S, Akaza H, Miki T, et al. Bladder cancer develops 6 years earlier in current smokers: analysis of bladder cancer registry data collected by 
the cancer registration committee of the Japanese Urological Association. Int J Urol 2009; 16:64.

14. Harshman LC, Preston MA, Bellmunt J, Beard C. Diagnosis of bladder carcinoma: a clinician's perspective. Surg Pathol Clinics. 2015;8(4):677-85.

15. Mayorga GE, Ibarra OI, Sedano BJ, Trujillo OL, Cornejo DV, Palmeros RA, et al. Application of nomograms in Mexico for bladder cancer in patients of the General Hospital "Dr. Manuel Gea González ". Mexican J Urol. 2014;74(1):3-8.

16. Sun M, Trinh QD. Diagnosis and staging of bladder cancer. Hematol/ Oncol Clinics. 2015;29(2):205-18.

17. Gormley EA, Lightner DJ, Faraday M, Vasavada SP. Diagnosis and treatment of overactive bladder (nonneurogenic) in adults: AUA/SUFU guideline amendment. J Urol. 2015;193(5):1572-80.

18. Telli O, Sarici H, Ozgur BC, Doluoglu OG, Sunay MM, Bozkurt S, et al. Urothelial cancer of bladder in young versus older adults: clinical and pathological characteristics and outcomes. Kaohsiung J Med Sci. 2014;30(9):466-70.

19. White N, Iglesia CB. Overactive bladder. Obstet Gynecol Clin N Am. 2016;43(1):59-68.

20. Cidre MJ, López-Fando L, Esteban M, Franco A, Arlandis S, Castro D, et al. How should we address the diagnosis of overactive bladder in women? Spanish Urological Records. 2016;40(1):29-36.
21. Aw HC, Ranasinghe W, Tan PH, O'Connell HE. Overactive pelvic floor muscles (OPFM): improving diagnostic accuracy with clinical examination and functional studies. Translational Androl Urol. 2017;6(Suppl 2):S64.

22. Ngo B, Perera M, Papa N, Bolton D, Sengupta S. Factors affecting the timeliness and adequacy of haematuria assessment in bladder cancer: a systematic review. BJU Int. 2017;119:10-8.

23. Niemi MA, Cohen RA. Evaluation of microscopic hematuria: a critical review and proposed algorithm. Adv Chronic Kidney Dis. 2015;22(4):289-96.

24. Atta MA, Kotb AF, Sharafeldeen M, Elabbady A, Hashad MM. The value of extended good quality transurethral resection of bladder tumour in the treatment of the newly diagnosed bladder cancer. Arab J Urol. 2017;15(1):60-3.

Cite this article as: Rafaelano AJM, Navarro JJA, Sosa MIT, Reyes FL, Gutiérrez MP. Urothelial bladder carcinoma with major clinical presentation as overactive bladder, without hematuria: case report and literature review. Int J Reprod Contracept Obstet Gynecol 2018;7:4292-6. 